\title{
Refracture of the Tibial Post after Posterior-Stabilized Total Knee Arthroplasty: Case Report and Literature Review
}

\author{
T. Vivacqua* (D) I. M. da Palma, R. P. Albuquerque, V. Favilla, J. Rezende, R. Rezende, K. Mesquita \\ National Institute of Traumatology and Orthopedics, Rios D’Or Hospital, Rio de Janeiro, Brazil \\ Email: ^drthiagovivacqua@gmail.com
}

How to cite this paper: Vivacqua, T., da Palma, I.M., Albuquerque, R.P., Favilla, V., Rezende, J., Rezende, R. and Mesquita, K. (2020) Refracture of the Tibial Post after Posterior-Stabilized Total Knee Arthroplasty: Case Report and Literature Review. Open Journal of Orthopedics, 10, 1-5. https://doi.org/10.4236/ojo.2020.101001

Received: November 16, 2019

Accepted: December 22, 2019

Published: December 25, 2019

Copyright $\odot 2020$ by author(s) and Scientific Research Publishing Inc. This work is licensed under the Creative Commons Attribution International License (CC BY 4.0).

http://creativecommons.org/licenses/by/4.0/

\begin{abstract}
Background: Tibial polyethylene wear is related late failure in total knee arthroplasty. The cruciate substitute design depending on the cam-post mechanism to secure the knee cinematics after a posterior stabilized total knee arthroplasty (PS-TKA). A post fracture can occur after damage failure of the post. Aim: Report a case of post refracture after a PS-TKA and review the lecture about post wear in PS-TKA. Case presentation: A 63 woman with a primary TKA had a diagnosis of polyethylene post fracture. The polyethylene exchange wasn't enough and revisions of all components were necessary. Conclusion: In patient with previous well function, subtle swelling and giving away sings after PS-TKA, a post fracture must be excluded.
\end{abstract}

\section{Keywords}

Total Knee Arthroplasty, Tibial Postfracture, Post Breakage,

Posterior-Stabilized, Polyethylene Failure

\section{Introduction}

Total knee arthroplasty (TKA) is a treatment option for patients with advanced knee degenerative disease [1]. The statisticians projected 935.000 and 1260.000 primary TKAs per year, by 2030 [2].

The posterior stabilized total knee arthroplasty (PS-TKA) design with a tibial polyethylene post and femoral cam was created to optimize knee kinematics and maintain flexion stability after resected the posterior cruciate ligament [3] [4]. The cam-post interface is exposed to constant wear and damage in PS-TKA design [3]. Tibial polyethylenepost damage due to failure fracture is a major problem and revision knee arthroplasty indication [5] [6]. The present study reports 
on a case of refracture of the polyethylene post of a PS-TKA leading to the necessity of a re-revision surgery.

\section{Case Report}

A 63-year woman was operated upon for a right total knee replacement on December 2010. The prosthesis was a PSOptetrak ${ }^{\oplus}$. On May 2016, she felt a snap on her knee followed by a sensation of instability. Clinically, there was anteroposterior femorotibial instability, small effusion and pain (Figure 1).

The computer tomography (CT) scan images did reveal a rectangular image resembling a fragment of the polyethylene post (Figure 2), which leads us to diagnose a fracture of the polyethylene post. A revision surgery with exchange of the polyethylene component was undertaken on October 2016. This new polyethylene component was $2 \mathrm{~mm}$ thicker than the original to avoid hyperextension of the knee and anterior impingement of the tibial post.

One year after that revision surgery, on November 2017, the patient returned with another snap followed by pain and a mild effusion. At surgery a broken fragment of the tibial polyethylene post was found (Figure 3).

She was then offered a re-revision operation with the implantation of a semi-constrained prosthesis. The procedure was performed on January 2018.The joint remains painfree, stable and with a good range of movement at one-year follow-up. The final surgical and $\mathrm{x}$-rays images show prosthetic components in place and well positioned (Figure 4). The patient had given her consent for the case report to be published.

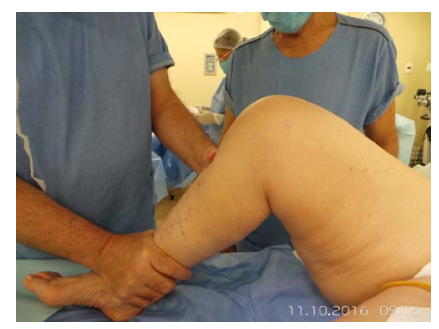

Figure 1. Images depicting instability due to posterior displacement of the tíbia relative to the femur at $90^{\circ}$ of flexion (author data).

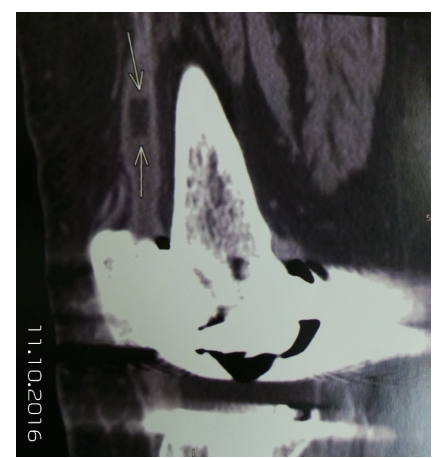

Figure 2. CT scan with the polyethylene fragment at the suprapatellar pouch (gray arrows) (author data). 


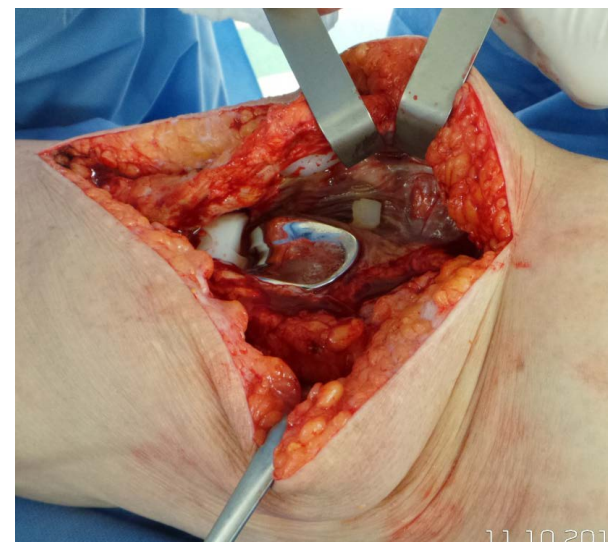

Figure 3. The polyethylene fragment at the suprapatellar pouch (author data).

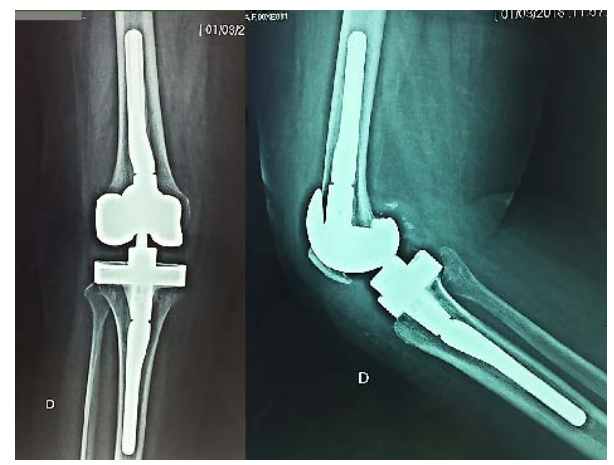

Figure 4. Radiological views of the revision prosthesis (author data).

\section{Discussion}

The fracture of the polyethylene post after a PS-TKA is a potential but not common complication leading to a revision procedure, and had a frequency estimated in $0.52 \%$ with a specific manufacture prothesis [4].

The knee hyperextension position must be avoided after PS-TKA. Watanabe et al. [7] reported on the kinematic analysis of 40 well-functioning total knee arthroplasties (Actiyas ${ }^{\circledR}$ ) and concluded that one-third of the knees with high-flexion PS-TKA had anterior impingement at the final of the gait stance phase and at the initial swing phase. To avoid anterior post impingement, they advised the posterior tibial slope must be cut with at $5^{\circ}$ or less of posterior inclination.

Puloski et al. [3] described the polyethylene wear patter in 23 retrieved components from four different manufacturers. The predominant wear mechanism was adhesive. Severe wear with delamination was identified in 30\% of the posts. The posterior surface of the post was the most predominant wear localization. The author makes a point of the cam-post interface is note an innocuous articulation.

Dolan et al. [8] evaluated three different polyethylene inserts to compare the tibial post wear. The Optetrak ${ }^{\circledR}$ design demonstrated a typical anterior post wear damage considering the anterior localization of the post in this prothesis. The 
NexGen ${ }^{\circledR}$ design demonstrated a relatively equal distribution of wear damage in the post surface and in the Genesis ${ }^{\circledR}$ design the posterior surface of the post was more affect considering the typical posterior position of post in this prothesis.

Bal et al. [5] in a series of 564 arthroplasties reported on $12 \%$ knees that required revision due to failure of the tibial post with a Foundation-100 series Total Knee System ${ }^{\odot}$. The prevalence clinical signs were instability and pain. They also draw attention to the multifactorial etiology of post failures and that the cam-post design may not be suitable for high-demand patients. In our case the typical clinical history is a previous well function PS-TKA and a sudden symptom of pain, swelling and giving away. The diagnosis can be confirmed after a positive posterior drawer test at flexion position of the knee.

Diamond et al. [5] described five cases of fracture of a polyethylene tibial post after PS-TKA. All patients had the NexGen LPS-High Flex ${ }^{\circledast}$ total knee implants characterized with a highly cross-linkedpolyethylene. In a previous series of the same surgeon with 2566 cases and using the conventional ultra-high molecular weight polyethylene (UHMWPE) any post fracture was described. The conventional UHMWPE polyethylene may be less susceptible to wear damage and consequent fatigue fracture. The author suggested that the high flexion (HF) could be related with the post fracture.

Paterson et al. [9] matched 20 retrieved HF inserts with 20 retrieved PS insets form Genesis implant system. The backside and tibial post wear scores were greater in the HF inserts. The wear damage in rounded and square tibial post design were analyzed with three-dimensional prothesis models. Less stress concentration was identified during flexion with hyperextension and rotation in the rounded tibial post [10].

In our case, the failure of the polyethylene post which leads to the first revision occurred after five-year follow-up. The typical design of the tibial polyethylene post of the Optetrak ${ }^{\circledast}$ placed more anteriorly than that of other prosthesis along with technical flaws during the surgical procedure, specially placing the femoral component into flexion, may have contributed to the early failure seen in this case. A femoral component in flexion position must be avoided in order to minimize anterior impingement of the tibial post. During the revision surgery the position of femoral component was correct and knee hyperextension was avoided with a well extension gap balance. In the moment of last appointment the patient has a functional knee without any complaint.

\section{Conclusion}

The polyethylene wear is one cause of early failure in TKA. In patient with previous well function, subtle swelling and giving away sings after PS-TKA, a post fracture must be excluded. This is, to our knowledge, the first report of a polyethylene tibial post refracture and draws attention to the necessity of recognizing technical details related to prothesis design and surgical procedure to avoid this complication. 


\section{Conflicts of Interest}

The authors state no conflicts.

\section{References}

[1] Thiele, K., Perka, C., Matziolis, G., Mayr, H.O., Sostheim, M. and Hube, R. (2015) Current Failure Mechanisms after Knee Arthroplasty Have Changed: Polyethylene Wear Is Less Common in Revision Surgery. The Journal of Bone and Joint Surgery, 97, 715-720. https://doi.org/10.2106/JBJS.M.01534

[2] Sloan, M., Premkumar, A. and Sheth, N.P. (2018) Projected Volume of Primary Total Joint Arthroplasty in the U.S., 2014 to 2030. The Journal of Bone and Joint Surgery, 100, 1455-1460. https://doi.org/10.2106/JBJS.17.01617

[3] Puloski, S.K.T., McCalden, R.W., MacDonald, S.J., Rorabeck, C.H. and Bourne, R.B. (2001) Tibial Post Wear in Posterior Stabilized Total Knee Arthroplasty. An Unrecognized Source of Polyethylene Debris. The Journal of Bone and Joint Surgery-American Volume, 83, 390-397. https://doi.org/10.2106/00004623-200103000-00011

[4] Diamond, O.J., Howard, L. and Masri, B. (2018) Five Cases of Tibial Post Fracture in Posterior Stabilized Total Knee Arthroplasty Using Prolong Highly Cross-Linked Polyethylene. Knee, 25, 657-662. https://doi.org/10.1016/j.knee.2018.05.005

[5] Bal, B.S., Greenberg, D., Li, S., Mauerhan, D.R., Schultz, L. and Cherry, K. (2008) Tibial Post Failures in a Condylar Posterior Cruciate Substituting Total Knee Arthroplasty. Journal of Arthroplasty, 23, 650-655.

https://doi.org/10.1016/j.arth.2007.08.002

[6] Kumar, N., Yadav, C., Raj, R. and Yadav, S. (2015) Fracture of the Polyethylene Tibial Post in a Posterior Stabilized Knee Prosthesis: A Case Report and Review of Literature. Journal of Orthopaedics, 12, 160-163.

https://doi.org/10.1016/j.jor.2015.01.002

[7] Watanabe, T., Aoki, A., Hoshi, K., Muneta, T., Sekiya, I. and Koga, H. (2019) Anterior Tibial Post Impingement during Stair Climbing: A Kinematic Analysis and Clinical Outcomes. Journal of Arthroplasty, 34, 379-384. https://doi.org/10.1016/j.arth.2018.10.027

[8] Dolan, M.M., Kelly, N.H., Nguyen, J.T., Wright, T.M. and Haas, S.B. (2011) Implant Design Influences Tibial Post Wear Damage in Posterior-Stabilized Knees. Clinical Orthopaedics and Related Research ${ }^{\circledR}$, 469, 160-167. https://doi.org/10.1007/s11999-010-1515-1

[9] Paterson, N.R., Teeter, M.G., MacDonald, S.J., McCalden, R.W. and Naudie, D.D. (2013) The 2012 Mark Coventry Award: A Retrieval Analysis of High Flexion versus Posterior-Stabilized Tibial Inserts. Clinical Orthopaedics and Related Research ${ }^{\infty}$ 471, 56-63. https://doi.org/10.1007/s11999-012-2387-3

[10] Watanabe, T., Koga, H., Horie, M., Katagiri, H., Sekiya, I. and Muneta, T. (2017) Post-Cam Design and Contact Stress on Tibial Posts in Posterior-Stabilized Total Knee Prostheses: Comparison between a Rounded and a Squared Design. Journal of Arthroplasty, 32, 3757-3762. https://doi.org/10.1016/j.arth.2017.07.010 